\title{
EDITORIAL
}

\section{Retos de inclusión comunitaria}

\author{
Jazmín Muñoz Gálvez \\ Profesora del Departamento de Ciencias Humanas \\ de la Universidad Autónoma de Manizales \\ https://orcid.org/0000-0003-1735-8693 \\ https://doi.org/10.30854/anf.v28.n51.2021.852
}

La película Xala (1975), del escritor, director y activista político senegalés Ousmane Sembène, retrata con sarcasmo y potencia la corrupción de la nueva clase política y burguesa africana - en un contexto posterior a la independencia y constituido por democracias apenas nacientes-, un tema recurrente en sus películas que permite trazar una similitud con el actual destino geopolítico de América Latina dentro del panorama global de acumulación de capital financiero y de dependencias externas a los intereses de los Estados.

En Xala, El Hadji Abdou Kader Bèye es un hombre de negocios a punto de ser expulsado de la esfera empresarial y política debido a un conflicto de intereses con otros saqueadores de bienes públicos, lo que constituye para él una racha de mala suerte más que una impugnación de responsabilidades administrativas y legales. La connivencia entre las élites económicas y políticas que amenazan hoy la democracia a servicio de intereses privados, se representa en la siguiente declaración de El Hadji en la Cámara de Comercio de esta "ficticia” realidad Senegalesa:

—¿Qué somos nosotros?

- Somos los cazafortunas del mundo de los negocios. No redistribuimos más que sobras.

Hemos estado en el tráfico de arroz, y durante la sequía hemos desviado fondos destinados a los necesitados. El ejército e incluso las fuerzas de seguridad están en nuestra nómina. Democracia, igualdad y justicia son palabras que somos demasiado bajos para conocer.

La surreal confesión de El Hadji encarna una de las disfuncionalidades de las democracias actuales que coexisten con un creciente monopolio corporativo, 
restricciones financieras y corrupción que erosionan el terreno de la acción interventora de los Estados para preservar los derechos sociales y económicos de la población, y así, constituirse como un filtro ante la globalización económica. La división política, económica y cultural del mundo actual ha implicado que los ganadores de la globalización — al igual que en la película de Sembène-puedan crear las reglas de su propio distanciamiento social y, que al haber recogido "los frutos de la bonanza económica de los mercados, de las cadenas de suministro y de los flujos del capital globalizado dependan cada vez menos de sus conciudadanos, ya sea como productores o como consumidores" (Sandel, 2020; p.13). La burguesía senegalesa es representada por Sembéme como poco productiva; su falta de visión paraliza el desarrollo y es un catalizador de la alienación cultural de la nación.

Esta representación es también paralela a la crítica de la retórica del ascenso social que prima en el imaginario de la sociedad estadounidense, realizada por Michael Sandel en La tiranía del mérito, según la cual la sociedad que goza de amplios derechos actúa bajo la creencia de que el éxito o fracaso social en un sistema de libre mercado es producto del mérito, y que la desigualdad no requiere de un principio reparador, lo cual imposibilita la solidaridad. No obstante, el mérito se origina en una distribución desigual de oportunidades con base en privilegios hereditarios, naturales y de origen; y no meramente como producto del esfuerzo personal. Esto implica que se debe volcar la mirada al acceso a oportunidades, y poner en cuestión la defectuosa ética competitiva del mérito que gobierna el imaginario occidental y que confina a muchos ciudadanos a la clase social en la que nacen, cuyo objetivo no incentiva la movilidad social.

Además, la globalización orientada al mercado ha mostrado ser poco exitosa a la hora de enfrentarse a una crisis laboral, de salud pública y a la degradación ecológica generalizada que requiere de una acción conjunta; de acuerdo a fines que van más allá de la reafirmación de los intereses nacionales. Por ello, la democracia sigue constituyendo una meta para delimitar legítimamente los discursos, intereses y preocupaciones normativas enfrentadas a partir de la demanda creciente de variados sectores sociales de ampliar los beneficios de la producción de capital, generalizar el progreso y posibilitar una interacción más prudente y ética entre la sociedad y el medio ambiente. Esto permitiría la reestructuración de la confianza entre la población y el restablecimiento del tejido social roto por el poder monopólico.

Recientemente, la Comisión Económica para América Latina y el Caribe (CEPAL, 2021) indicó la importancia de "Impulsar políticas transversales y sectoriales para avanzar hacia un nuevo modelo de desarrollo” en Latinoamérica que permita la recuperación de una década de avance perdida para la región, debido a la crisis ambiental, social, económica y sanitaria propiciada por la Covid 
19. En su informe, incluye aspectos esenciales como la producción de políticas industriales y tecnológicas, la inversión estatal y la reestructuración del sistema educativo, sanitario y laboral. Además, debido a que la región soporta la mayor carga de la deuda externa en el PIB (56.3\%) se insta a la creación de "una nueva arquitectura financiera internacional que responda a la emergencia y al desarrollo de la región". El enfoque de la CEPAL (Cuevas, H., Julián, D., Rojas, J., 2018, p. 16) ha considerado que, si bien el desarrollo de Latinoamérica está supeditado a una dinámica global, es necesaria la inserción de la región en la competencia internacional, por lo que ha recomendado la implementación de una democracia desarrollista que permita expandir las posibilidades económicas más allá de las élites, y maximizar los recursos disponibles. También cuestiona el estancamiento de la región en un modelo agroexportador, así como la excesiva acumulación de la tierra.

No obstante, pese a las alternativas propuestas por académicos y movimientos sociales, se le sigue dando prioridad a la explotación de recursos por medio de industrias multinacionales, y "se delega el direccionamiento de la economía a las grandes empresas y al capital financiero” (Soussa, 2017, p. 292).

Es así como los verdaderos perdedores de la globalización no pueden vender su fuerza de trabajo ni comprar medios baratos con el fin de aumentar su productividad para su propio sostenimiento, como sucede con un amplio sector de la población rural pobre de muchos países de la periferia del desarrollo global. En la película Fango Suave (2016), del director letón Renars Vimba, se representa efectivamente esta polarización del desarrollo global y nacional, mediante un contexto muy cercano a la realidad de Letonia que hereda la desigualdad económica después de independizarse de la URSS, perdiendo gran parte de su población debido a la migración económica. Mediante una microhistoria, en esta película vemos cómo una joven adolescente y su hermano se enfrentan a la exclusión de un sistema que ofrece una educación incapaz de salvarlos de las circunstancias de desigualdad asociadas a su origen y ausencias paterna y materna. Las oportunidades de educación por sí mismas devienen infructuosas ante necesidades insatisfechas, vínculos emocionales rotos y paisajes erosionados. Este ejemplo de la ficción cinematográfica, insertado también en la realidad, permite plantear que la libertad de elección necesita de un análisis simétrico en el campo de la economía y de las relaciones sociales que integran lo político. Además, la equidad y la preocupación por la inclusión implican que los derechos políticos, sociales y económicos sean interdependientes.

Así, ante la crisis de dignidad de un contexto global en el que una gran mayoría de personas no son sujetos de derechos humanos y, pese a la confianza en el principio de autonomía democrática institucional, incluida en el enfoque de la CEPAL, este principio debe ser complementado con las demandas sociales de 
participación e inclusión por medio de variadas formas de un ejercicio democrático representativo, participativo, comunitario y discursivo. Por lo cual, persiste la contradicción existente entre las fuerzas y relaciones de producción, y una segunda contradicción entre fuerzas productivas y condiciones de producción que son palpables en la actual crisis social y ecológica que afecta a la región y al mundo. Las consecuencias socioambientales del modelo neoextractivo no son fácilmente reversibles, y es la sociedad civil históricamente excluida un actor activo que desafía la postura predominante sobre los límites para un desarrollo equitativo.

En este contexto, los procesos sociales y comunitarios locales son un actor participativo de regulación social no estatal. En dichos procesos existe una conciencia crítica de lo que está en juego mediante la generalización del neoextractivismo que considera al inversor como el protagonista de la vida económico-política. También se mantiene una amplia crítica a la consideración del crecimiento económico como un fin y no como un medio con ingentes sacrificios del nivel de vida, de la vida política y de la cosmovisión tradicional de las comunidades raizales que buscan no solo representación, sino participación institucional democrática.

A esto se suma que el modelo económico predominante ofrece muy poco al progreso fuera y dentro del mercado, para sectores principalmente rurales donde prevalece un mercado interno o local marginal; generalmente vinculado a procesos de asociación comunitarios pero que requieren de engranajes institucionales para constituir un desarrollo que proporcione un bienestar integral, de la mano de un enfoque de justicia territorial y social.

En el filme El vuelco del cangrejo (2009), del director Oscar Ruiz Navia, muestra una imagen cercana al documental de las comunidades afro descendientes del pacífico colombiano vallecaucano, ubicado en La Barra. Esta película suscita la reflexión sobre el papel del Estado en el acceso a derechos y en el desarrollo turístico y económico potencial de la región, mediante el fortalecimiento de las organizaciones comunitarias como una posibilidad de prosperidad viable en armonía con la memoria ancestral, la protección de la pluralidad cultural y étnica, el cuidado del medio ambiente y el acceso a oportunidades plurales de educación, cualificación técnica y acceso a medios de producción baratos.

Por ello, la creación de experiencias de desarrollo piloto que puedan ser monitoreadas por los Estados y evaluadas por los ciudadanos, desde los procesos de participación comunitaria, constituyen un reto de los Estados que no quieran perder su identidad definida bajo una paz democrática, en consonancia con múltiples formas de economía popular y fortalecimiento del tejido social. Con ocasión de este tipo de problemáticas, la revista Ánfora espera que las múltiples propuestas elaboradas en los artículos sirvan de inspiración para nuevas maneras de generar inclusión en las comunidades desde distintos frentes académicos y de reflexión. 


\section{Referencias}

CEPAL. (julio de 2021). La paradoja de la recuperación en América Latina y el Caribe. Crecimiento con persistentes problemas estructurales: desigualdad, pobreza, poca inversión y baja productividad. https://www.cepal.org/es/ publicaciones/47043-la-paradoja-la-recuperacion-america-latina-caribecrecimiento-persistentes

Cuevas, H., Julián, D., Rojas, J. (2018). América latina: expansión capitalista conflictos sociales y ecológicos. RIL Editores.

Ruiz, N. O. (Director). (2009). El vuelco del cangrejo [Película]. Contravía Films, Diana Bustamante Arizona Films

Sandel, M. (2020). La tiranía del mérito. ¿Qué ha sido del bien común? Debate.

Sousa, S. B. (2017). Democracia y transformación social. Siglo XXI Editores.

Sembène, O. (Director). (1975). Xala [Película]. Filmi Domireve SNC

Vimba, R. (Director). (2016). Es esmu šeit [Fango Suave] [Película]. Tasse Film 